\title{
A REVIEW ON ANTECEDENTS OF CITIZEN'S TRUST IN GOVERNMENT SOCIAL MEDIA SERVICES
}

\section{Sohrab Khan}

Advanced Informatics School, Universiti Teknologi Malaysia, Kuala Lumpur, (Malaysia)

E-mail: meersohrab@gmail.com

Nor Zairah Ab. Rahim

Advanced Informatics School, Universiti Teknologi Malaysia, Kuala Lumpur, (Malaysia)

E-mail: nzairah@utm.my

Nurazean Maarop

Advanced Informatics School, Universiti Teknologi Malaysia, Kuala Lumpur,

(Malaysia)

E-mail: nurazeanmaarop@gmail.com 


\section{ABSTRACT}

In recent years, social media has been accepted as a practice of e-government services across the world. Unlike static government websites, social media is an interactive communication platform that helps government organizations to improve their relationship with citizens through participation and engagement. However potential values of social media cannot be displayed without addressing citizen's acceptance and their trust to participate in government social media services. Majority of previous studies on the relationship of trust between government and public are conducted on static government websites using general technological characteristics. This paper provides a comprehensive literature review of the relevant articles to explore multiple antecedents or factors of citizen's trust with a major consideration in using social media as a technology platform for e-government services. A model is proposed that identifies individual characteristics, government factors, risk factors and social media characteristics as multiple antecedents of citizen's trust in government social media services.

\section{KEYWORDS}

Antecedents of trust; e-government; government social media; citizen's trust, factors.

\section{INTRODUCTION}

E-government is the employment of information and communication technologies (ICTs) by government to provide services to citizens, business partners and different government offices [1]. The goal of e-government is to enrich government online services and their quality of interactions with citizens and businesses partners through good quality services and systems. According to Khan [2] investment in e-government, also known as Government 1.0, has enabled government organizations to be more transparent, effective, and efficient than early traditional service delivery mechanisms.

In recent years the development of e-government services has migrated from static websites to social media, which is considered as part of Web 2.0 platform [3]. As stated by Hao, Zheng and Zeng [4], the benefits of social media are not limited only to individuals and private sectors organizations. Social media also provides unique opportunities for government organizations to make effective use of it to provide services to citizen's as per their desire and needs. Government organizations in different countries have started using social media to build closer ties with citizens and increase their participation in government services [5,6]. The statistics show that the usage of social media by governments across the world is increasing rapidly with the number more than three times from 2010 to 2012 and with another 50 per cent rise in 2014 [7]. Social media is regarded as an influential tool to activate citizen-government engagement. It facilitates online communication and relationship building between government and citizens through information sharing and non-discriminative participation [8]. Social media has the capability to increase legitimacy of government organizations through communication and coordination between multiple stakeholders. Government organizations can integrate the information obtained from citizens into policy making and thus increase transparency through information sharing and collaboration with public to reach solutions for government problems. The citizens at the same time can get the opportunity to communicate and express their opinions on government policies and quality of services in real time environment [6]. The government use of social media is supported to strengthen citizen's interactivity [9], increase government transparency [10] 
and perception of trustworthiness [11]. However, the efforts of governments and the potential value of government social media services cannot be displayed without addressing citizens willingness and their trust to participate in these services $[4,8]$.

Several studies have been conducted to investigate the relationship of trust between people and government [1,12]. Bélanger and Carter [13] identified trust as a significant predictor of citizen's intention to use an e-government service. Similarly, Abu-Shanab [14], mentioned that the gate to e- government adoption is trust. This was supported by Chen, Jubilado, Capistrano and Yen [15] by highlighting trust as an essential determinants for e-government adoption. Though previous studies have reflected trust as the most significant dimension to influence citizens behavior towards e-government adoption. However, majority of those studies are limited on e-government websites using internet as a technology to provide e-government services. In addition, majority of them have addressed partial issues with limited consideration only about trust in internet and trust in government. Very little attention has been paid on citizen's trust perspective in online government services [12]. On the contrary there is very little research on using social media as a technology in government organizations[4]. Despite of increased popularity in using social media by governments across the world, its acceptance among citizen's is still a serious issue and has not gained much attention in previous studies [16]. Prior studies have identified trust as a significant factor in using social media or social networking sites at user level [17] and firm level [18] but have failed to cover multiple perspective of citizen's trust in context of using government social media services. Some studies have also investigated the relationship of social media with interactivity [4], participation [4] and to increase citizen's trust on institutions and their services [5,9]. However, the major contributors or factors of citizen's trust to participate in government social media services are still unexplored.

Trust is a major concern that develops citizens acceptance to participate with government and use its online services [19, 20]. Al-Khouri [21] mentioned about the need to develop citizen's trust if their acceptance and participation in e-government services are to be promoted. Therefore, this can be argued that citizen's trust on government social media services must be developed a way before they start using these services. It is important to explore the major contributors to develop citizen's trust to gain an understanding about their behavior towards government social media services. The objective of this paper is to identify those factors, which can influence citizen's trust to participate in government social media services. This paper contributes in literature by exploring antecedents of citizen's trust from multiple dimensions with a major focus in using social media as a technology for electronic government services. The identified factors are categorized, and an integrated model is proposed to provide a comprehensive understanding of different trust dimensions. The findings of this paper can help government organizations to better understand citizen's needs and design their policies accordingly to increase citizen's trust and participation in government social media services.

\section{METHODOLOGY}

A literature review was conducted on citizen's trust perspectives and their participation in e-government and social networking services. The search was carried out through seven electronic databases: that are ACM, Science Direct, IEEE, Scopus, Springer link, Taylors and Francis and Google Scholar. These databases were chosen as they provide 
the most important and high impact full-text journals and conference proceedings, covering the fields of e-government, social media, social networking sites and government social media services. The Keywords were chosen in respect of factors Influencing Citizens Trust which include: "Trust", "Citizens Trust", "E government", "Factors", "Government social media", "social networking services". The resulted articles were thoroughly analyzed to extract most relevant articles meeting the research needs of this paper to identify antecedents of trust in government social media. Initially 291 articles were identified through database searches. The duplicate studies, short papers and the articles related with e-government or social media implementation, challenges, strategies and showing government organizations perspective were not included in this paper. Thus, 32 articles were selected which were more relevant about trust factors influencing citizen's behavior. In addition, reference lists of selected articles were scanned to identify any further relevant articles that were not found in the initial search. As a result, total number of 36 articles were found relevant to identify trust factors in context of government social media services.

\section{THEORETICAL FOUNDATION AND RELATED STUDIES ON ANTECEDENTS OF TRUST}

The field of Information systems and Technology has always attracted researchers' interest to investigate the theories and models that have the power in predicting and explaining behavior. To provide a solid theoretical basis for selecting influential trust factors in government social media services, this paper integrates two important streams of literature. First is the Technology acceptance model (TAM) [22], which is an adaptation of Theory of reasoned action (TRA) [23] and secondly, the literature on multiple dimensions of citizen's trust [12-14, 24].

TAM is one of the most popular research model that was developed to predict behaviour in IT usage [3]. TAM seeks to conceptually understand and explain an individual's intention about IT system usage, based on two perceptions. The first is the user's perception regarding whether it will help his or her performance of relevant tasks. This is referred to as perceived usefulness (PU). The second perception is the user's perception regarding the effort required to use a system. This is referred to as perceived ease of use (PEOU). Both these perceptions about the technology are said to shape the intention to use, which in turn shapes the actual use of the technology. The value of TAM in context of e-government [12, 25] and social networks [3] has been consistently important. TAM is considered as most successful adoption model as per the number of studies on online behavior relying on TAM and its high explanatory power [26]. TAM as a standalone model might not sufficiently explain the intention and use of the technology but has the flexibility to be extended and adapted to different features by integrating additional constructs from other models and cognitive studies [26]. TAM is considered as one of the best frameworks to understand technology adoptions and this can be extended or adapted easily to different features in many diverse situations [26]. The connections between trust and TAM has been discussed in previous literature showing a significant relationship of PEOU (perceived ease of use) and PU (perceived usefulness) with trust in different contexts of online environments [27]. This paper contributes to integrate antecedents of trust with TAM in context of government social media services which is a new practice of e-government services. This paper will determine how multiple dimensions of citizen's trust integrated with TAM can affect citizen's intention to participate in government social media services. 
Trust refers to the willingness of one party to become vulnerable to others based on their characteristics [28, 29]. Trust has been studied in various disciplines including psychology, sociology, computer science, business and organizational sciences. In each field Trust, has been interpreted differently, which causes complexity in defining trust. Because of its multidimensional nature trust has attracted attention from multiple perspectives and thus there are various definitions of trust in literature [24]. The literature shows that majority of previous studies have viewed technology and government factors as important antecedents of trust in using online government services [30-32]. For instance, Wang and $\mathrm{Lu}$ [32] stated that trust in government and trust in internet are main factors that determine citizen trust on e-government. This was supported by Chen, et al. [15] in their study by identifying trust in technology and trust in government as essential factors influencing trust in e-government websites. There are very few studies that have addressed multiple perspectives of citizen's trust in using government services $[12,14]$. One of the study was conducted by Beldad, Geest, Jong and Steehouder [33] who categorized trust in online environment into three dimensions: which are Internet user based, Organization based and Web based determinants of trust in online environment. In a recent article Alzahrani, et al. [12] carried out a systematic literature review on citizens trust aspects and categorized them as technology factors, government factors, risk factors and citizen's characteristics. Beside technological and government factors they highlighted the consideration of risk related factors and psychological aspects of individuals in determining their trust towards e-government services. However, their study was limited on e-government websites considering general technological characteristics.

The context of this paper is on government social media services with a focus on social media characteristics instead of focusing on technology characteristics in general. In this study, social media is being used as a technology platform to provide government services, contrary to the previous studies where Internet was used as a tool to provide services from static government websites [12, 14, 15]. Based on the study of Alzahrani, et al. [12] the trust factors are categorized in to multiple dimensions which are individual characteristics, government factors, risk factors and social media characteristics. These factors are discussed and a summary is presented in this section:

\subsection{Individual characteristics}

The citizen's aspects (trustor) and their beliefs regarding other party influence trust [12, 33]. Many researchers have highlighted propensity or disposition of trust as an important contributors towards trust in e-government [11-13, 34]. Colquitt, Scott and LePine [35] stated that disposition to trust is a personality-based trust which plays a key role in shaping trust even in the presence of trustworthiness information. Disposition of trust refers the general tendency to trust others. It represents the willingness of individuals to engage in a trusting relationship with others based on their own beliefs. This factor differs among individuals based on their personality, experiences and cultural values [36]. The importance of disposition to trust was also validated by Colesca [24] in context of citizens trust in e-government services. According to Bélanger and Carter [13], some people tend to trust on other things or online entities even without having much information about them, whereas some require great deal on information to place their trust on any target. So, high level of disposition of trust increases trust and low level of disposition to trust decreases trust. This is especially important in initial phases of building relationships [13]. 
Using social media services in government organizations is still in its infancy, thus disposition of trust can have some impact on citizen's trust on these services. Hence this paper also considers disposition to trust as a significant factor in context of using government social media services.

\subsection{Government factors}

Citizen-Government relationship plays a central role in forming trust towards adoption of government services [37]. Many researchers agree that trust in government and its institutions is a very significant dimension leading to the successful adoption of government services $[12,19,38]$. Previous literature has interpreted trust in three sub dimensions: Ability, integrity and benevolence. Ability refers to the skills and competencies of government organizations to influence different stakeholders within some domain. Benevolence represents the extent to which a trustee (government organizations) was to do good for the trustor (citizens) apart from any motive of benefits or profits. Integrity represents the extent to which citizens believe that government organizations will adhere to a set of rules or principles which may include their truthfulness, promise fulfilment and justice [35]. Gefen, Karahanna and Straub [39] stated that these beliefs can generate trust in individuals in which they do not feel vulnerable toward risk in online environment with government organizations. Similarly, Scherer and Wimmer [34] and Bélanger and Carter [13] also mentioned Ability, Benevolence and Integrity as significant factors of perceived trustworthiness. Thus, based on the above discussion these government factors should directly affect citizen's trust in using government social media services.

\subsection{Risk factors}

Risk may be described as a fear of losing personal information and fear of being monitored on the Internet [38]. A strong correlation between risk and trust has been identified in previous studies of trust relationship on online government and social networking services [12]. Two important technological risks have been found more important in context of online services which are security and privacy [12]. Privacy risk relates to the loss of control over personal information whereas, security is related with unauthorized access to individual's personal data is using government social media services. Ayyash, Ahmad and Singh [40] indicated the positive influence of both security and privacy in context of e-government services. Similarly, Ranaweera [25] also found a positive relationship between perceived security and perceived privacy on citizens trust in e-government services. This means that the more users perceived their security and privacy in using government social media services, the more they tend to trust in using these services. Using social media for government services is a new phenomenon and citizens might feel concerns in using this technology to use government services. Therefore, this paper also considers these technological risks, which are security and privacy as an antecedent of trust in using government social media services.

\subsection{Social media characteristics}

Social media is used as a technology platform in context of government social media services. According to Beldad, et al. [33] characteristics of any technology influence citizens trust in using that technology. Similarly, Park, et al. [8] mentioned that citizen's trust towards the government can increase if the government understands the characteristics of social media and then utilize them appropriately. Therefore, it's 
important to identify those technological characteristics which may influence citizens trust in using government social media services.

Structural assurance leads to Institution based trust [28], which ensures that there is existing support (legal, contractual or physical) to use a technology. This relates positively in generating trust towards any specific technology. According to McKnight, et al. [29] structural assurance reflects that account and privacy settings and policies are designed and in place in the technology to keep user's information safe. Structural assurance promotes confidence because users believe that there are policies and mechanism in place to keep their critical information safe from unauthorized access. This helps in addressing user's concerns regarding protection form uncertainties in using a technology [29]. The importance of structural assurance and its relationship with trust has been validated in different domain of online services [29, 39]. In context of government social media, government organizations post a lot of information about their services and other activities so there might be a need of structural assurance to attract a good number of citizens to participate.

Previous research has indicated that information quality has a significant impact on citizens trust. For instance, Lee and Lei [41] stated that citizen's perception about usefulness of e-government service is related in terms to access their required information more effectively than traditional ways. Similarly, authors like Nicolaou and McKnight [42], Park, et al. [8] and Weerakkody, Irani, Lee, Hindi and Osman [43] stated good quality information as a significant antecedent to generate trust. The results of previous studies have found that if the e-government website provides accurate and timely information, users tend to use that technology for government services. According to Ayyash, et al. [40], a good information quality information (timely, up to date, comprehensive, relevant) will develop citizens trust to use e-government services. There are variety of information on social networking services generated by multiple users. Thus, it can be argued that reliable, relevant and timely information can affect citizen's trust and can be considered as antecedents of trust in government social media services. Perceived ease of use and perceived usefulness are two main constructs in the Technology acceptance model (TAM). In this study perceived ease of use is described as the degree to which citizen's feel that using government social media services is easy to use and free from efforts. Perceived usefulness in this study represents the degree to which citizen's believe that using government social media services is better and more effective than traditional ways or using static e-government websites for getting government information and services [44]. Davis [22] stated that both of these perceptions shape the intention to use, which in turn shapes the actual use of the technology. Previous studies have found a positive relationship of perceived ease of use and perceived usefulness towards citizens trust [26, 40]. For instance, Hassanein and Head [44] identified perceived ease of use and perceived usefulness as important determinants of online trust. Similarly, Alsaghier and Hussain [23] also validated a positive relationship of perceived ease of use and perceived usefulness with trust in egovernment websites. This paper also considers both perceived ease of use and perceived usefulness as antecedents of citizens trust in context of using government social media services. In addition, based on previous studies using TAM, this paper also considers a direct effect of both components (perceived ease of use and perceived usefulness) with citizens intention to participate in context of government social media services. 
Based on the above discussion, this paper identifies Individual characteristics, government factors, perceived risk and social media characteristics as antecedents of trust in government social media services. The findings illustrated from above discussion are summarized in Table 1.

Table 1. Factors influencing citizen's trust in government social media services.

\begin{tabular}{|l|l|l|}
\hline Antecedents of Trust & Constructs & Sources \\
\hline \multirow{4}{*}{ Individual characteristics } & Disposition to Trust & $\begin{array}{l}{[13,23,24,35,36,} \\
39]\end{array}$ \\
\hline \multirow{4}{*}{$\begin{array}{l}\text { Sovernment factors } \\
\text { Risk factors }\end{array}$} & Ability & {$[29,35,45,46]$} \\
\cline { 2 - 3 } & Benevolence & {$[29,35,45,46]$} \\
\cline { 2 - 3 } & Integrity & {$[29,35,45,46]$} \\
\hline \multirow{3}{*}{ media } & Security risk & {$[14,25,40,47]$} \\
\cline { 2 - 3 } & Privacy risk & {$[14,25,40,47]$} \\
\cline { 2 - 3 } & Information quality & {$[14,25,40,43]$} \\
\cline { 2 - 3 } & Structural assurances & {$[29,39,48]$} \\
\cline { 2 - 3 } & Perceived Ease of Use & {$[23,26,39,40,44]$} \\
\cline { 2 - 3 } & Perceived Usefulness & {$[23,40,44]$} \\
\hline
\end{tabular}

\section{PROPOSED RESEARCH MODEL}

An integrated model has been developed based on the relevant literature about trust factors in e-government adoption, social networking sites and related studies about government social media services. The model illustrated in Figure 1 provides a holistic view of citizen's trust factors in government social media services from multiple dimensions. These are Individual characteristics, Government factors, Risk factors and Social media characteristics, identified as antecedents of trust in government social media. Both TAM constructs i.e. Perceived ease of use and Perceived usefulness directly influence trust in government social media services and are directly related towards Intention to participate in these services. Furthermore, this study also contributes to examine the influence of trust on citizen's intention to participate in government social media services. The literature has illustrated a positive connection between trust and citizens intention to adopt a technology. The findings from the study of Alsaghier and Hussain [23] show a significant positive effect of trust in e- government service on citizen's intention to use these services. Similarly, the study conducted by Abu-Shanab [14] also found a significant relationship of trust on citizen's intention to adopt e-government services. Moreover, Scherer and Wimmer [34] claimed that social trust in e-participation positively affects citizen's usage intention. They argued that citizens are more likely to engage in e-participation activities if they trust their governments to take their opinions into consideration. The lack of trust will discourage their level of e-participation. Furthermore, Alharbi, et al. [30] also found that trust in government, internet and social trust factors had a significant effect on Saudi citizens' intention to engage in eparticipation on e-government websites. Based on the above discussion this can be argued that developing trust is an essential requirement to shape citizens behaviour is using e-government services. Therefore, this paper presents trust as a significant predictor towards citizen's intentions to participate in government social media services. 


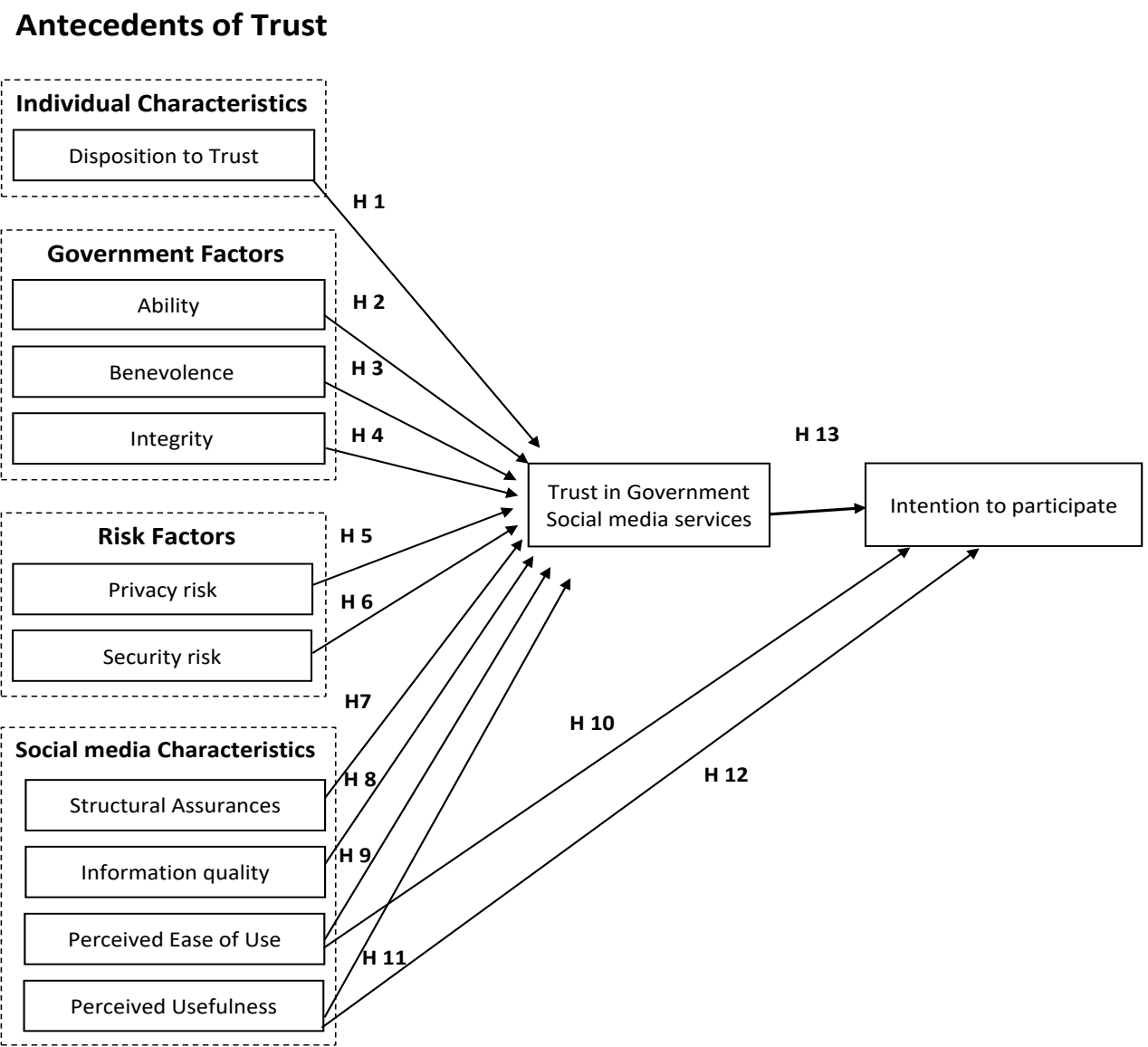

Figure 1. Antecedents of Trust in government social media services.

\section{CONCLUSIONS, CONTRIBUTIONS AND LIMITATION}

Government social media has been accepted as a practice of e-government services across the world. While majority of prior research was conducted on e-government websites with limited focus only on technology and government factors, this paper contributes to explore the factors influencing citizen's trust in government social media from multiple dimensions. This paper identifies four factors that are citizen's characteristics, government factors, risk factors and social media characteristics, as antecedents of citizen's trust in government social media. This paper further presents the impact of citizens trust towards their intention to participate in government social media services. The antecedents of citizen's trust in government social media services must be investigated to enable government organizations to enhance their abilities to devise policies and strategies based on citizen's needs and their willingness to participate in government social media services. This paper aims to contribute at both a theoretical and empirical level towards an improved understanding of using social media in the government context. The antecedents in the proposed model are derived from previous empirical evidences and theories. This makes the proposed model more reliable and viable that creates a basis upon which studies may be conducted to identify citizen's trust factors with different samples of different nations for making assessment and comparisons from the collected data.

There are some limitations in this paper. The first limitation of this paper is its restriction to focus only on citizen's trust perspective towards government social media services. This paper does not cover government organizations, policy maker's perspective regarding 
their social media plans, strategies or any other associated challenges in social media implementation and maintenance issues. In addition, the relationships between various trust antecedents with each other is also not covered in this study.

\section{REFERENCES}

[1] P. B. Shah and N. Lim, Using Social Media to Increase E-Government Adoption in Developing Countries, Proceedings of the 5th International Conference on Theory and Practice of Electronic Governance, ICEGOV '11, (2011), Tallin, Estonia.

[2] G. F. Khan, The Government 2.0 utilization model and implementation scenarios, Information Development, vol. 31, no. 2, pp. 135-149, (2015).

[3] J. W. F. Leung, Social media in e Government, An empirical study of adoption factors and consequences, The Univeristy of Newcastle Australia, (2014).

[4] X. Hao, D. Zheng, and Q. Zeng, How to strenghthen social media interactivity of egovernment, Online Information Review, Emerald Group Publishing Limited, vol. 40, no. 1, pp. 79-96, (2016).

[5] H. Hong, Government websites and social media's influence on government-public relationships, Public Relations Review, vol. 39, no. 4, pp. 346-356, (2013).

[6] M. J. Park, D. Kang, J. J. Rho, and D. H. Lee, Policy role of social media in developing public trust: Twitter communication with government leaders, Public Management Review, vol. 18, no. 9, pp. 1265-1288, (2016).

[7] UN, United Nations E Government Survey: E-Government for the Future we want. Department of Economic and Social Affairs, New York, 2014.

[8] J. M. Park, H. Choi, K. S. Kim, and J. J. Rho, Trust in government's social media service and citizen's patronage behavior, Telematics and Informatics, vol. 32, pp. 629-641, (2015).

[9] A. M. Warren, A. Sulaiman, and N. I. Jaafar, Social media effects on fostering online civic engagement and building citizen trust and trust in institutions, Government Information Quarterly, vol. 31, no. 2, pp. 291-301, (2014).

[10] C. Song and J. Lee, Citizens' Use of Social Media in Government, Perceived Transparency, and Trust in Government, Public Performance \& Management Review, vol. 39, no. 2, pp. 430-453, (2016).

[11] G. A. Porumbescu, Comparing the Effects of E-Government and Social Media Use on Trust in Government: Evidence from Seoul, South Korea, Public Management Review, vol. 18, no. 9, pp. 1308-1334, (2016).

[12] L. Alzahrani, W. Al-Karaghouli, and V. Weerakkody, Analysing the critical factors influencing trust in e-government adoption from citizens' perspective: A systematic review and a conceptual framework, International Business Review, vol. 26, no. 1, pp. 164-175, (2017).

[13] F. Bélanger and L. Carter, Trust and risk in e-government adoption, The Journal of Strategic Information Systems, vol. 17, no. 2, pp. 165-176, (2008).

[14] E. Abu-Shanab, Antecedents of trust in e-government services: An empirical test in Jordan, Transforming Government: People, Process and Policy, Article vol. 8, no. 4, pp. 480-499, (2014).

[15] J. V. Chen, R. J. M. Jubilado, E. P. S. Capistrano, and D. C. Yen, Factors affecting online tax filing - An application of the IS Success Model and trust theory, Computers in Human Behavior, vol. 43, pp. 251-262, (2015).

[16] A. Alarabiat, Electronic Participation Through Social Media: Citizens' Adoption Factors at Local Government Level, Proceedings of the 9th International Conference on Theory and Practice of Electronic Governance, (2016), pp. 424-427: ACM. 
[17] R. M. ALotaibi, M. Ramachandran, A.-L. Kor, and A. Hosseinian-Far, Factors Affecting Citizens' use of Social Media to Communicate with the Government: a Proposed Model, Electronic Journal of e-Government, vol. 14, no. 1, (2016).

[18] F. Parveen, N. I. Jaafar, and A. Sulaiman, Role of Social Media on Information Accessibility, 19th Pacific Asia conference on Information Systems (PACIS), (2015).

[19] P. Franks and M. Driskill, Building Trust in Government through Social Media: An InterPARES Trust Research Project, European conference on Social media, (2014), University of Brighton, UK.

[20] S. A. Mousavi and E. Pimenidis, Social Media Applications in e-Government: A Risk Assessment Approach, 14th European Conference on eGovernment, (2014), Romania.

[21] A. M. Al-Khouri, E-government in Arab countries: A 6-staged roadmap to develop the public sector, Journal of management and Strategy, vol. 4, no. 1, p. 80, (2013).

[22] F. D. Davis, Perceived usefulness, perceived ease of use, and user acceptance of information technology, MIS quarterly, pp. 319-340, (1989).

[23] H. Alsaghier and R. Hussain, Conceptualization of trust in the e-government context: A qualitative analysis, in Active Citizen Participation in E-Government: A Global Perspective IGI Global, (2012).

[24] S. E. Colesca, Understanding trust in e-government, Engineering Economics, vol. 63, no. 4, (2009).

[25] H. M. B. P. Ranaweera, Perspective of trust towards e-government initiatives in Sri Lanka, SpringerPlus, journal article vol. 5, no. 1, p. 22, (2016).

[26] D. Belanche, L. V. Casaló, and C. Flavián, Integrating trust and personal values into the Technology Acceptance Model: The case of e-government services adoption, Cuadernos de Economía y Dirección de la Empresa, vol. 15, no. 4, pp. 192-204, (2012).

[27] I.-L. Wu and J.-L. Chen, An extension of Trust and TAM model with TPB in the initial adoption of on-line tax: An empirical study, International Journal of HumanComputer Studies, vol. 62, no. 6, pp. 784-808, (2005).

[28] D. H. Mcknight, M. Carter, J. B. Thatcher, and P. F. Clay, Trust in a specific technology: An investigation of its components and measures, ACM Trans. Manage. Inf. Syst., vol. 2, no. 2, pp. 1-25, (2011).

[29] D. H. McKnight, V. Choudhury, and C. Kacmar, Developing and validating trust measures for e-commerce: An integrative typology, Information systems research, vol. 13, no. 3, pp. 334-359, (2002).

[30] A. Alharbi, K. Kang, and I. Hawryszkiewycz, The Influence of Trust and subjective Norms on Citizens Intentions to Engage in E-participation on E-government Websites, Australian Conference on Information Systems (2015), Adelaide.

[31] W. H. S. Alkhilani and H. Sulaiman, Identification of factors influencing G2C services acceptance in developing countries, International Conference on Information Technology and Multimedia (ICIMU), (2014), Putrajaya, Malaysia.

[32] T. Wang and Y. Lu, Determinants of Trust in E-Government, International Conference on Computational Intelligence and Software Engineering (CiSE) (2010).

[33] A. Beldad, T. Geest, M. Jong, and M. Steehouder, A cue or two and I'll trust you: Determinants of trust in government organizations in terms of their processing and usage of citizens personal information disclosed online, Government information Quarterly, (2012).

[34] S. Scherer and M. A. Wimmer, Conceptualising Trust in E-Participation Contexts, presented at the International Conference on Electronic Participation, (2014),

[35] J. A. Colquitt, B. A. Scott, and J. A. LePine, Trust, trustworthiness, and trust propensity: a meta-analytic test of their unique relationships with risk taking and job performance, Journal of applied psychology, vol. 92, no. 4, p. 909, (2007). 
[36] H. Kivijärvi, A. Leppänen, and P. Hallikainen, Technology Trust: From Antecedents to Perceived Performance Effects, $46^{\text {th }}$ International Conference on System Sciences (HICSS), (2013), Hawaii.

[37] T. S. H. Teo, S. C. Srivastava, and L. Jiang, Trust and electronic government success: An empirical study, (in English), Journal of Management Information Systems, Article vol. 25, no. 3, pp. 99-131, (2009).

[38] M. Rehman, V. Esichaikul, and M. Kamal, Factors influencing e-government adoption in Pakistan, Transforming Government: People, Process and Policy, vol. 6, no. 3, pp. 258-282, (2012).

[39] D. Gefen, E. Karahanna, and D. W. Straub, Trust and TAM in online shopping: an integrated model, MIS quarterly, vol. 27, no. 1, pp. 51-90, (2003).

[40] M. M. Ayyash, K. Ahmad, and D. Singh, Investigating the effect of information systems factors on trust in e-government initiative adoption in palestinian public sector, Research Journal of Applied Sciences, Engineering and Technology, Article vol. 5, no. 15, pp. 3865-3875, (2013).

[41] C. B. P. Lee and U. L. E. Lei, Adoption of e-government services in Macao, 1st international conference on Theory and practice of electronic governance, (2007), Macao, China, 1328102.

[42] A. I. Nicolaou and D. H. McKnight, Perceived information quality in data exchanges: Effects on risk, trust, and intention to use, Information systems research, vol. 17, no. 4, pp. 332-351, (2006).

[43] V. Weerakkody, Z. Irani, H. Lee, N. Hindi, and I. Osman, Are U.K. Citizens Satisfied With E-Government Services? Identifying and Testing Antecedents of Satisfaction, Information Systems Management, vol. 33, no. 4, pp. 331-343, 2016/10/01 (2016).

[44] K. Hassanein and M. M. Head, The influence of product type on online trust, 17th Bled Electronic Commerce Conference (2004), Slovenia.

[45] M. A. Fuller, M. A. Serva, and J. Baroudi, Clarifying the integration of trust and TAM in e-commerce environments: implications for systems design and management, IEEE Transactions on Engineering Management, vol. 57, no. 3, pp. 380-393, (2010).

[46] R. C. Mayer and J. H. Davis, The effect of the performance appraisal system on trust for management: A field quasi-experiment, Journal of applied psychology, vol. 84, no. 1, p. 123, (1999).

[47] S. S. Alam, M. Ahmad, A. A. Khatibi, and M. N. Ahsan, Factors affecting trust in publishing personal information in online social network: An empirical study of Malaysia's Klang Valley users, Geografia: Malaysian Journal of Society and Space, vol. 12, no. 2, pp. 132-143, (2016).

[48] R. Pennington, H. D. Wilcox, and V. Grover, The role of system trust in business-toconsumer transactions, Journal of Management Information Systems, vol. 20, no. 3, pp. 197-226, (2003). 